\title{
SOIL MOISTURE RETRIEVAL WITH AIRBORNE PALS INSTRUMENT OVER AGRICULTURAL AREAS IN SMAPVEX16
}

\author{
Andreas Colliander ${ }^{1}$, Thomas J. Jackson ${ }^{2}$, Mike Cosh $^{2}$, Sid Misra ${ }^{1}$, Rajat Bindlish ${ }^{2}$, Jarrett Powers ${ }^{3}$, \\ Heather McNairn', Paul Bullock ${ }^{4}$, Aaron Berg ${ }^{5}$, Ramata Magagi ${ }^{6}$, Peggy O'Neill', and Simon Yueh ${ }^{1}$
}

\author{
${ }^{1}$ Jet Propulsion Laboratory, California Institute of Technology, CA, USA \\ ${ }^{2}$ USDA ARS Hydrology and Remote Sensing Laboratory, MD 20705, USA \\ ${ }^{3}$ Agriculture and Agri-Food Canada, Canada \\ ${ }^{4}$ University of Manitoba, Canada \\ ${ }^{5}$ University of Guelph, Canada \\ ${ }^{6}$ University of Sherbrooke, Canada \\ ${ }^{7}$ Goddard Space Flight Center, MD, USA
}

\begin{abstract}
NASA's SMAP (Soil Moisture Active Passive) calibration and validation program revealed that the soil moisture products are experiencing difficulties in meeting the mission requirements in certain agricultural areas. Therefore, the mission organized airborne field experiments at two core validation sites to investigate these anomalies. The SMAP Validation Experiment 2016 included airborne observations with the PALS (Passive Active L-band Sensor) instrument and intensive ground sampling. The goal of the PALS measurements are to investigate the soil moisture retrieval algorithm formulation and parameterization under the varying (spatially and temporally) conditions of the agricultural domains and to obtain high resolution soil moisture maps within the SMAP pixels. In this paper the soil moisture retrieval using the PALS brightness temperature observations in SMAPVEX16 is presented.
\end{abstract}

Index Terms - SMAP, SMAPVEX16, PALS, Soil Moisture, Brightness Temperature

\section{INTRODUCTION}

NASA's (National Aeronautics and Space Administration) Soil Moisture Active Passive (SMAP) mission was launched in January 2015. The objective of the mission is global mapping of soil moisture and freeze/thaw state [1]. Well characterized sites with calibrated in situ soil moisture measurements are used to determine the quality of the soil moisture data products; these sites are designated as core validation sites (CVS) [2]. To support the CVS based validation airborne field experiments are used to provide high-fidelity validation data and to improve the SMAP retrieval algorithms.

The SMAP project and NASA coordinated airborne field experiments at three CVS locations in 2015 and 2016. SMAP
Validation Experiment 2015 (SMAPVEX15) was conducted around the Walnut Gulch CVS in Arizona in August, 2015 [3]. SMAPVEX16 was conducted at the South Fork CVS in Iowa and Carman CVS in Manitoba, Canada from May to August 2016 (see Figure 1). The main objective of SMAPVEX15 was to understand the effects and contribution of heterogeneity on the soil moisture retrievals, whereas the main objective of SMAPVEX16 was to understand the anomalous retrieval behavior observed over the South Fork and Carman CVS.

Each campaign featured the airborne PALS (Passive Active L-band Sensor) instrument [4]. The PALS instrument mapped the SMAPVEX15 experiment area 7 times and the SMAPVEX16 domains were each mapped 12 times (altogether 30 coincidental measurements). Each campaign was accompanied with intensive ground sampling regime consisting of manual sampling and augmentation of the CVS soil moisture measurements with temporary networks of soil moisture sensors. This paper focuses on the soil moisture retrieval from PALS observations in SMAPVEX16.

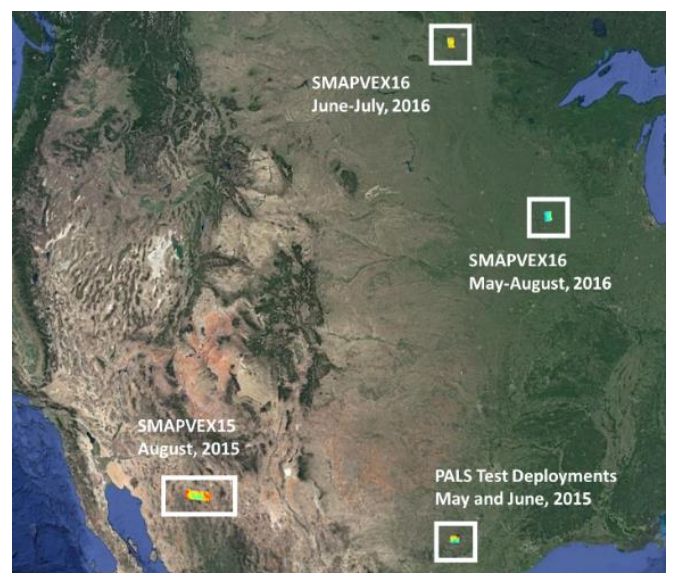

Figure 1. Locations of PALS test deployments (Texas) and SMAPVEX15 (Arizona) and SMAPVEX16 (Iowa and Manitoba). 


\section{SMAPVEX16}

SMAPVEX16 was conducted in Iowa during May 25-June 5, 2016 and August 2-16, 2016, and in Manitoba, Canada during June 8-20, 2016 and July 10-22, 2016. The activities were focused on the SMAP Core Validation Sites (CVS) called South Fork in Iowa and Carman in Manitoba. The first Intensive Observation Periods (IOP) occurred during the low vegetation part of the season and the second IOPs occurred during the high vegetation part of the season. Each of the CVS have a network of permanently installed soil moisture sensors that provide an estimate of the average soil moisture within the SMAP pixels.

Each IOP included six PALS deployments to measure brightness temperature (TB) and normalized radar crosssection, and intensive in situ measurements including manual sampling and temporary soil moisture sensor networks. The PALS measurements were conducted at two altitudes: a higher altitude of about $3 \mathrm{~km}$ was used to map the entire domain (about $6 \mathrm{~km}$ swath, $1.5 \mathrm{~km}$ spatial resolution) and lower altitude of about $1.2 \mathrm{~km}$ was used for field scale measurements (about $2 \mathrm{~km}$ swath, $600 \mathrm{~m}$ spatial resolution). The manual sampling included soil moisture measurements with dielectric probes and core samples, vegetation measurements for vegetation water content and structure, and surface roughness measurements.

Both South Fork and Carman are dominated by agricultural activity. In South Fork crops are corn (70\%) and soybeans $(30 \%)$. In Carman the most significant crop types are soybeans $(30 \%)$, wheat $(24 \%)$, canola $(18 \%)$, corn $(8 \%)$ and oats (7\%). During SMAPVEX16 the weather conditions were mostly favorable but in general during the IOPs the ground was relatively wet. There was enough variability, however, for extracting the information needed to address the SMAP algorithm anomalies. Figure 2 shows the time series of the soil moisture evolution for South Fork based on the permanent network. The range of average soil moisture is from $0.17 \mathrm{~m}^{3} / \mathrm{m}^{3}$ to $0.42 \mathrm{~m}^{3} / \mathrm{m}^{3}$ during the IOPs.

\section{PALS}

The PALS instrument collects coincident (in time and place) radar and radiometer measurements ([4], [5]). Both measurements are obtained through the same antenna in a fast-switching sequence. During SMAPVEX15 and SMAPVEX16, PALS was installed on a DC-3 aircraft. In this configuration PALS employed a lightweight antenna with a $21^{\circ}$ beamwidth [6], which had been upgraded to include a scanning mechanism. The PALS antenna was attached to a scan head under the fuselage of the aircraft allowing a full $360^{\circ}$ conical scan at $40^{\circ}$ incidence angle, which matches the observing angle of SMAP.

The operation of the PALS radiometer is based on an internal two-reference calibration scheme; this design was adopted for the radiometers deployed by the SMAP [7] and Aquarius missions [8]. The two loads allow the removal of internal gain and offset fluctuation of the radiometer chain during operation. The brightness temperature at the input of the antenna is computed using the principles presented in [9].

\section{SOIL MOISTURE RETRIEVAL ALGORITHM}

The soil moisture retrieval algorithm uses an approach that is based on the standard $\tau$ - $\omega$ formulation for vegetation (e.g., [10]) but applies a modified form for the roughness parameter. This approach uses variable roughness correction based on the soil moisture similarly to the method applied in [11] which was developed for retrieving soil moisture in the Carman domain. In the $\tau$ - $\omega$ formulation the top of the vegetation brightness temperature is modeled using soil reflectivity $\left(r_{\text {soil }}\right)$, vegetation opacity $(\tau)$ and vegetation scattering parameter $(\omega)$ :

$$
\begin{aligned}
T_{B, p}^{T O V} & =\left(1-r_{\text {soil }, p}\right) T_{\text {soil }} e^{-\tau_{p}} \\
& +T_{\text {veg }}\left(1-\omega_{p}\right)\left(1-e^{-\tau_{p}}\right) \\
& +T_{\text {veg }}\left(1-\omega_{p}\right)\left(1-e^{-\tau_{p}}\right) r_{\text {soil }, p} e^{-\tau_{p}},
\end{aligned}
$$

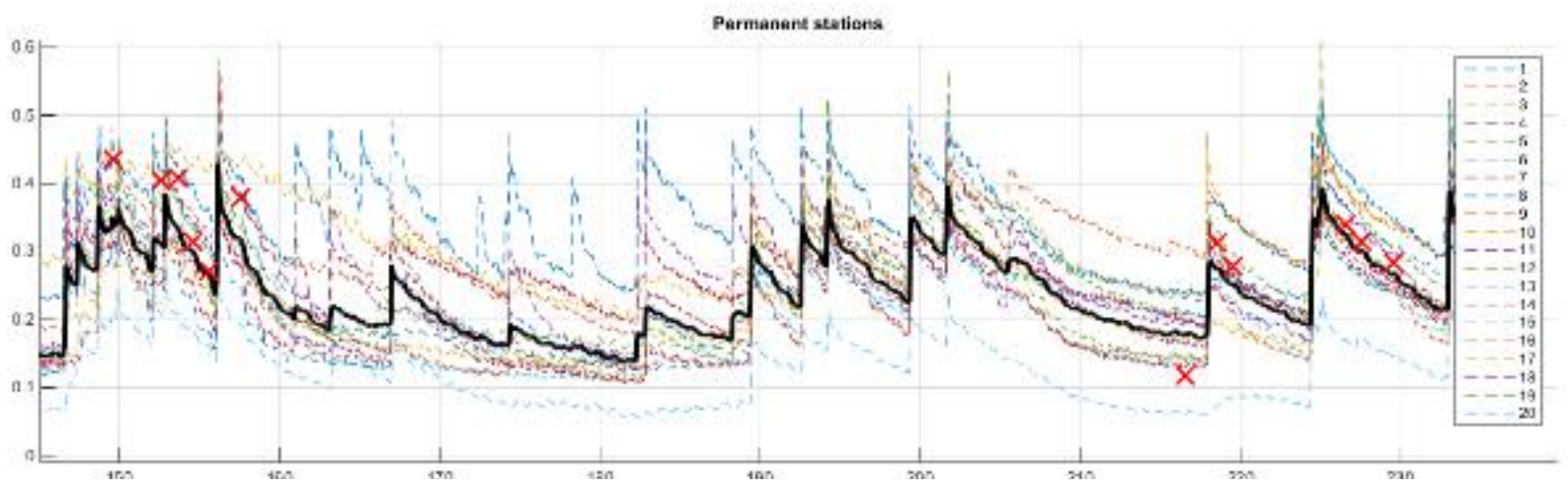

Figure 2. Soil moisture time series over South Fork in Iowa. The thick black line represents the weighted average of the in situ sensors. The individual sensors are depicted with dashed lines. The average of the PALS soil moisture retrieval over the domain is marked with red crosses. 

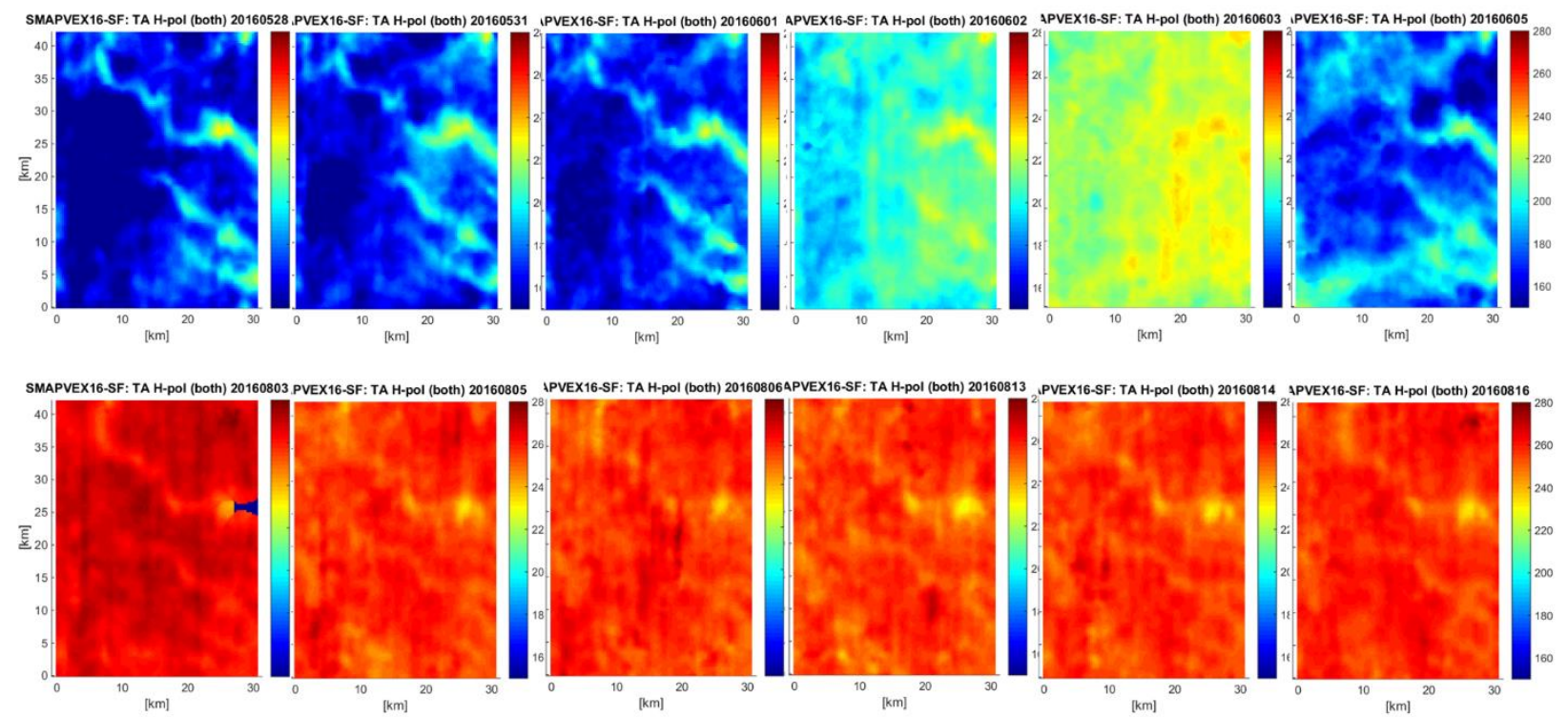

Figure 3. PALS horizontally polarized brightness temperatures for the deployment over the South Fork site in Iowa. The top row displays the maps for the IOP1 and the bottom row for the IOP2.

where the first term corresponds to the ground emission through the vegetation, the second term to the vegetation emission, and the third term to the vegetation emission dwelling downward and then reflected from the ground and propagated through the vegetation. According to [11] the traditional roughness formulation is augmented with reflectivity correction parameter $C_{p}$ :

$$
r_{\text {soil }, p}=r_{0, p} e^{-C_{p} h_{0, p} \cos ^{2}(\theta)}, h_{0, p}=(2 \sigma k)^{2}
$$

where $r_{0, p}$ is the flat surface reflectivity; $\theta$ is the incidence angle; $\sigma$ is the root mean square deviation of the surface height, and $k$ is the wave number in free space. The smooth surface reflectivity is related to soil dielectric constant through the Fresnel reflection coefficient. The soil dielectric constant is related to soil moisture using the Mironov model [12].

\section{RESULTS}

\subsection{PALS Brightness Temperature}

Figure 3 shows the gridded high-altitude horizontally polarized PALS brightness temperature maps for the deployment over the South Fork site in Iowa. It is evident from the images that the brightness temperatures were overall significantly higher during IOP 2 . As evidenced by Figure 2 this is not due to lower soil moisture content but a result of the dense vegetation layer. During IOP1 the ground was essentially bare (apart from the river surroundings which are covered by some woodlands and visible as higher brightness temperature, for example, in the top left-hand side plot of
Figure 3).

Figure 4 shows a comparison of the PALS TB observations with respect to the SMAP TB observations over both South Fork and Carman sites. The mean difference (shown in the legend) is removed from the plot. The comparison shows that the vertical polarizations have unbiased RMS difference of $1.9 \mathrm{~K}$ and horizontal polarizations have that of $4.4 \mathrm{~K}$ (the range of horizontal polarization is larger). Considering the sensitivity of TB to soil moisture this is a reasonable result for the preliminary calibration of PALS. Further calibration efforts are expected to reduce the mean difference between PALS and SMAP.

\subsection{PALS Soil Moisture Retrieval}

Using the approach discussed in Section 4 the PALS brightness temperature observations were translated to soil moisture. The soil and vegetation temperatures were assumed

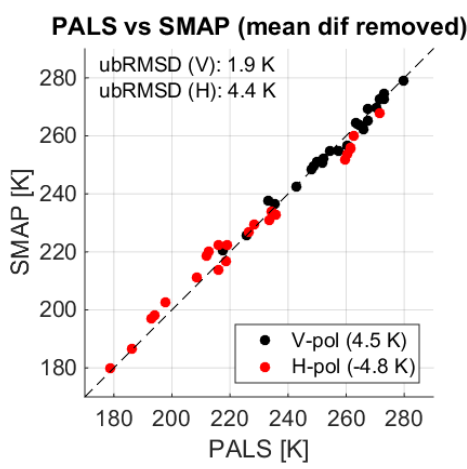

Figure 4. PALS TB plotted with respect to the SMAP TB for vertical and horizontal polarization. The mean difference is removed from the plot and shown in the legend. 
equal and were estimated using the soil temperature measurements of the permanent network. Vegetation Water Content was obtained using NDVI from MODIS. IGBP land cover classification was used for the land cover map and World Harmonized Soils Database for soil texture information.

Figure 2 shows the average PALS soil moisture over the South Fork domain for IOP1 and 2. During IOP1 the soil moisture seems to be overestimated in many cases. During IOP2, the averages seem to be closer but on the first day there is a serious underestimation. Figure 5 shows the retrieved soil moisture maps for the two of the dry-downs observed with the PALS flights. The plots on left-hand side column correspond to the dry-down on June 1-3 and the plots on the right-hand side correspond to the dry-down on August 13-16. Based on Figure 2, the image on top-left is overly wet, otherwise the average soil moistures in these plots correspond well to the in situ average (based on the permanent stations). While the soil moisture change during these dry-down events was about the same, the first dry-down has TB range of about $40 \mathrm{~K}$ and the second only about $5 \mathrm{~K}$. The muted signal is due to the full grown vegetation which was absent during IOP1. It is significant that PALS can resolve the soil moisture accurately under the full grown corn canopy during IOP2. Obviously, the retrieval becomes more susceptible to measurement noise and other error sources in the second case. The algorithm parameterization requires further tuning to make retrieval consistent with the in situ measurements. The low-altitude flights and all in situ measurements, including manual sampling and temporary networks will be included in this work.

\section{CONCLUSIONS}

Preliminary results for the soil moisture retrieval from the PALS instrument during SMAPVEX16 were presented in this paper. The final version of the paper will include results also from the Carman site, retuned algorithm and validation using all in situ data collected during the experiment.

\section{ACKNOWLEDGEMENT}

This work was carried out in part at Jet Propulsion Laboratory, California Institute of Technology under contract with National Aeronautics and Space Administration.

\section{REFERENCES}

[1] D. Entekhabi, et al., "The Soil Moisture Active Passive (SMAP) Mission," Proc. IEEE, vol. 98, no. 5, pp. 704-716, 2010.

[2] A. Colliander, T.J. Jackson, R. Bindlish, S. Chan, et al., "Validation of SMAP Surface Soil Moisture Products with Core Validation Sites," Rem. Sens. Env., Under Review.

[3] A. Colliander, M.H. Cosh, S. Misra, T.J. Jackson, W.T. Crow, S. Chan, R. Bindlish, C-S. Chae, C. Holifield Collins, S. Yueh, "Validation and Scaling of Soil Moisture in a Semi-Arid Environment: SMAP Validation Experiment 2015 (SMAPVEX15)," Rem. Sens. Env., Under Review.
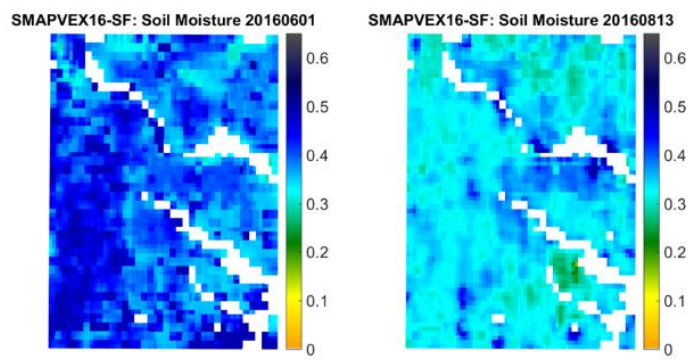

SMAPVEX16-SF: Soil Moisture 20160602
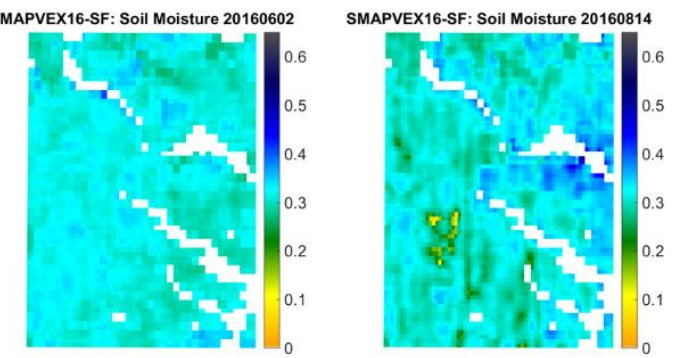

SMAPVEX16-SF: Soil Moisture 20160603
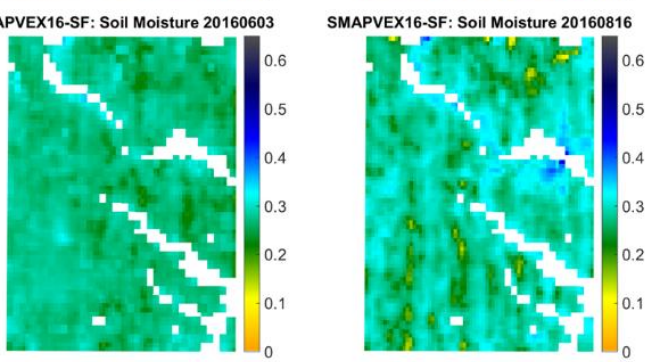

Figure 5. PALS soil moisture retrievals over South Fork. Lefthand side column: dry-down during IOP1 (June 1-3). Right-hand side column: dry-down during IOP2 (August 13-16). The blanked areas correspond to woodlands around the rivers.

[4] W. Wilson, et al., "Passive Active L- and S-Band (PALS) Microwave Sensor for Ocean Salinity and Soil Moisture Measurements," IEEE Trans. Geosci. Rem. Sens., Vol. 39, No. 5, 2001.

[5] S. Misra, et al.,. Radiometric Calibration of the Rotating Passive and Active L-band Airborne System. IEEE Geosci. Rem. Sens. Lett., Submission.

[6] S. Yueh, et al., "Passive and Active L-Band System and Observations during the 2007 CLASIC Campaign," Proc. IEEE International Geoscience and Remote Sensing Symposium 2008, Vol. 2, pp. II-241 II-244, 7-11, July 2008.

[7] J. Piepmeier, P. Mohammed, G. De Amici, E. Kim, J. Peng, C. Ruf. SMAP Algorithm Theoretical Basis Document (ATBD) L1B Radiometer Brightness Temperature Data Product: L1B_TB. SMAP Project, Goddard Space Flight Center, Greenbelt, MD, 2016.

[8] D. Le Vine, et al., "Aquarius: An Instrument to Monitor Sea Surface Salinity From Space”, IEEE Trans. Geosci. Rem. Sens., Vol. 45, No. 7, pp. 2040-2050, 2007.

[9] A. Tanner, W. Wilson, and F. Pellerano, "Development of a high stability L-band radiometer for ocean salinity measurements", Proc. IEEE Geosci. Rem. Symp., pp. 1238-1240, 2003.

[10] E.G. Njoku and D. Entekhabi, "Passive Microwave Remote Sensing of Soil Moisture," J. Hydrology, Vol. 184, pp. 101-129

[11] A. Colliander, E.G. Njoku, T.J. Jackson, S .Chazanoff, H. McNairn, J. Powers, M.H. Cosh, "Retrieving Soil Moisture for Non-Forested Areas Using PALS Radiometer Measurements in SMAPVEX12 Field Campaign,” Rem. Sens. Env., Vol. 184, pp. 86-100, 2016.

[12] V.L. Mironov, L.G. Kosolapova, S.V. Fomin, "Physically and Mineralogically Based Spectroscopic Dielectric Model for Moisture Soils," IEEE Trans. Geosci. Rem. Sens., Vol. 47, No. 7, pp. 20592070, 2009. 